\title{
EcoRI Analysis of Bacteriophage P22 DNA Packaging
}

\author{
E'thel Noland Jackson, David A. Jackson and Robert J. Deans \\ Department of Microbiology, The University of Michigan Medical School \\ Ann Arbor, Mich. 48109, U.S.A.
}

(Received 18 May 197\%, and in revised form 9 September 197\%)

\begin{abstract}
Bacteriophage P22 linear DNA molecules are a set of circularly permuted sequences with ends located in a limited region of the physical map. This mature form of the viral chromosome is cut in headful lengths from a concatemeric precursor during DNA encapsulation. Packaging of P22 DNA begins at a specific site, which we have tormed pac, and then procecds soquentially to cut lengths of DNA slightly longer than one complete set of P22 genes (Tye et al., 1974b). The sites of DNA maturation events have been located on the physical map of EcoRI cleavage sites in P22 DNA. EcoRI digestion products of mature P22 wild-type DNA were compared with EcoRI fragments of two deletion and two insertion mutant DNAs. These mutations decrease or increase the length of the genome, but do not alter the DNA encapsulation mechanism. Thus the position of mature molecular ends relative to $E c o R I$ restriction sites is different in each mutant, and comparison of the digests shows which fragments come from the ends of linear molecules. From the positions of the ends of molecules processed in sequential headfuls, the location of pac and the direction of encapsulation relative to the P22 map were deduced. The pac site lies in EcoRI fragment A, $4 \cdot 1 \times 10^{3}$ basepairs from EcoRI cleavage site 1. Sequential packaging of the concatemer is initiated at pac and proceeds in the counterclockwise direction relative to the circular map of P22. One-third of the linears in a population are cut from the concatemer at pac, and most packaging sequences do not extend beyond four headfuls.

Fragment $\mathrm{D}$ is produced by $E c o R I$ cleavage at a site near the end of a linear chromosome which has been encapsulated starting at pac. The position of the pac site is therefore defined by one end of fragment $D$. The pac site is not located near genes 12 and 18 , the only known site for initiation of P22 DNA replication, but lies among late genes at a position on the physical gene map approximately analogous to the cohesive end site (cos) of bacteriophage $\lambda$ at which $\lambda$ DNA is cleaved during encapsulation. Our results suggest that P22 and $\lambda$ DNA maturation mechanisms have many common properties.
\end{abstract}

\section{Introduction}

Each P22 bacteriophage particle contains a single molecule of linear, double-stranded DNA. The mature linear P22 DNA molecules isolated from a population of virus particles are circularly permuted and terminally redundant (Rhoades et al., 1968; Tye et al., 1974a,b). Streisinger et al. (1967) first suggested how circularly permuted, terminally redundant chromosomes could be generated during phage DNA encapsulation. Streisinger proposed that the intracellular precursor to the mature DNA is a concatemer, and the length of DNA cut from the concatemer equals the amount of DNA which will fit into the phage head, or one "headful". The length of one DNA 
headful can accommodate slightly more than one complete set of phage genes. Thus this headful encapsulation mechanism, cutting the concatemer either randomly or sequentially, will generate circularly permuted, terminally redundant linear DNA molecules.

Tye et al. (1974b) showed that mature P22 DNA molecules are formed during DNA encapsulation by a variation of the headful mechanism described by Streisinger. When circularly permuted and terminally redundant P22 DNA molecules were analyzed in the electron microscope after partial denaturation, the ends of these linear molecules were found to fall over less than $20 \%$ of the partial denaturation map. Tye et al. (1974b) proposed that this limited set of circularly permuted chromosomes could be produced by headful packaging of DNA if encapsulation begins at a specific site on the P22 DNA concatemer (Botstein \& Levine, 1968) and proceeds sequentially in one direction along the concatemeric precursor. A DNA encapsulation mechanism which begins at one site and cuts a limited number of sequential headfuls will produce terminally redundant, circularly permuted linear DNA molecules all having ends within a limited region of the genome if the terminal redundancy is small.

The experiments of Tye et al. $(1974 a, b)$ showed that, once encapsulation begins at the packaging initiation site, cutting of the concatemer by the headful packaging mechanism shows no site specificity. Partial denaturation mapping demonstrated that the presence of a large deletion or insertion in P22 DNA, which decreases or increases the length of the genome relative to the size of the headful, yields mature linear chromosomes with ends falling in all regions of the genome. Therefore, after the initial packaging event that begins a sequence of headfuls at a unique genetic location, the encapsulation mechanism can cut P22 DNA without any site specificity.

To generate the physical map of the P22 chromosome reported here and in the preceding paper, mature P22 DNA molecules were digested to a limit product with the restriction enzyme EcoRI. Digestion of linear P22 DNA produces fragments which can be separated by agarose gel electrophoresis to form eight bands. Several of these bands are unusual: the band migrating most slowly contains fragments that are quite heterogeneous in molecular weight, another band contains a fragment present in greatly reduced molar yield, and the molar yields of two other fragments are somewhat reduced. In contrast, restriction enzyme digestion of most viral DNAs, including DNA of the related bacteriophage $\lambda$, yields a set of discrete fragments present in equimolar amounts. The experiments reported here show that the anomalies in the P22 EcoRI fragment pattern are consequences of the limited circular permutation of P22 DNA and the mechanism by which concatemeric precursor DNA is matured and packaged.

In the accompanying paper (Jackson et al., 1978), seven of the eight fragments produced by digestion of P22 DNA by EcoRI were ordered. However, those experiments gave no information about the origin of the eighth fragment (fragment D), or about tho anomalies in the fragment pattern. In this paper, EcoRI digests of mature DNA of several P22 deletion and insertion mutants are compared with the wild-type P22 digestion products. These mutations alter the genome size, but not the packaging mechanism, so that the ends of permuted linear molecules fall in different regions of the physical map (Tye et al., 1974b). By considering the fragments produced by $E c o R I$ cleavage of the ends of these linears, we were able to infer the positions of maturation cleavages of the concatemeric DNA precursor relative to P22 EcoRI sites. Here we confirm that P22 DNA can be depicted as a circular array 
of seven EcoRI cleavage sites. We determine the physical location of ends of mature linear molecules of the wild-type P22 DNA and the deletion and insertion mutants. From these results we construct maps of the physical locations of DNA maturation events on wild-type P22 DNA and the insertion and deletion DNAs. The description of P22 DNA packaging contained in these maps defines the origin of fragment D and accounts for all the other anomalous features of an EcoRI digest of mature P22 DNA. Our results confirm by a different method the view of P22 DNA packaging proposed by Tye et al. (1974b) and provide more detailed information about the packaging process.

\section{Materials and Methods}

(a) Bacterial and bacteriophage strains

P22 Tc-10 carries an insertion of genetic material which includes genes determining tetracycline resistance (Watanabe et al., 1972; Chan et al., 1972; Tye et al., 1974a). Each particle of P22 Tc-10 is defective, since the complete genome will not fit into one P22 head. The complete genome of $\mathrm{P} 22 \mathrm{Tc}-10$ tet $^{\mathrm{R}} c 2-t s 30$, used here, was maintained in the prophage state and thermally induced to yield defective phage particles from which linear DNA was

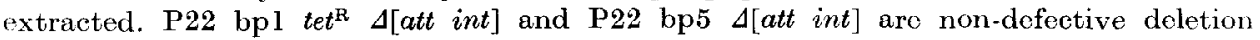
revertants of P22 Te-10 (Tye et al., 1974a, Chan \& Botstein, 1976). The prophage attachment site and integration gene are removed by the deletion in each phage. Both strains rotain part of the tet $t^{\mathrm{R}}$ insertion. The $\mathrm{P} 22 \mathrm{bp} 5$ strain used carried a clear plaque mutation (c2-am $\mathrm{O} 8)$, and a lysis mutation (13-am $\mathrm{H101}$ ). P22 pro-3 is a specialized transducing phage carrying an insertion including pro $\mathrm{A}$ and pro $\mathrm{B}$ of Salmonella typhimurium (Chan, 1974: Chan \& Botstein, 1976). P22 Tc-10 tet ${ }^{\mathrm{R}}$ c2-ts30, P22 bpl tet ${ }^{\mathrm{R}} \Delta[$ att int $], \mathrm{P} 22$ bp5 c2-am08 $13^{-} a m \mathrm{H} 10 \mathrm{~L}$ [att int], and $\mathrm{P} 22$ pro-3 were obtained from D. Botstein. Other phage and bacterial strains are described in the preceding paper (Jackson et al.. 1978).

\section{(b) Bacteriophage lysates}

Lysates of P22 c1-7 (wild type carrying a clear plaque mutation), P22 bpl tet $t^{\mathrm{R}}[$ att int]. P22 bp5 c2 amO8 13-amH101 $\Delta[$ att int], and P22 pro-3 were grown by infection of strain 18 as described in the preceding paper (Jackson et al., 1978). P22 Te-10 e2-ts30 was grown by heat induction. The lysogen $18\left(\mathrm{P} 22 \mathrm{Tc}-10\right.$ tet $\left.^{\mathrm{R}} c 2-t s 30\right)$ was grown in $\mathrm{L}$ broth at $32^{\circ} \mathrm{C}$ with aeration to about $3 \times 10^{8}$ cells $/ \mathrm{ml}$. The culture was then shifted to $40^{\circ} \mathrm{C}$, and vigorous aeration was continued until lysis.

\section{(c) Phage DNA preparations}

Unlabeled phage DNA was prepared as described in the preceding paper (Jackson et al., 1978).

\section{(d) Preparation of $1^{\prime 2} \% 2\left[{ }^{3} \mathrm{H}\right] D N A$}

P22 cl-7 was used to infect exponentially growing S. typhimurium LT2 strain 18 at a multiplicity of 5 phage/cell in M9 medium supplemented with $1.5 \%$ Casamino acids (Smith \& Levine, 1964). At the time of infection, deoxyadenosine and $\left[{ }^{3} \mathrm{H}\right]$ thymidine (20 Ci $/ \mathrm{mmol}$; New England Nuclear Corp., Boston, Mass.) were added to concentrations of $100 \mu \mathrm{g} / \mathrm{ml}$ and $10 \mu \mathrm{Ci} / \mathrm{ml}$, respectively. The culture was incubated at $37^{\circ} \mathrm{C}$ with aeration by shaking until lysis. Bacterial debris was removed by centrifugation at $9000 \mathrm{revs} / \mathrm{min}$ for $10 \mathrm{~min}$ in a JA20 rotor in the Beckman J21 centrifuge. The lysate was layered over a 7 - $\mathrm{ml}$ shelf of $5.65 \mathrm{M}-\mathrm{CsCl}\left(\rho=1.7 \mathrm{~g} / \mathrm{cm}^{3}\right)$ in a cellulose nitrate centrifuge tube and centrifuged for $2 \mathrm{~h}$ at $22,000 \mathrm{revs} / \mathrm{min}$ in a Beckman sW27 rotor. The phage band was removed from the top of the tube with a Pasteur pipet and added to $4.0 \mathrm{M}-\mathrm{CsCl}\left(\rho=1.5 \mathrm{~g} / \mathrm{cm}^{3}\right)$. All $\mathrm{CsCl}$ solutions were prepared in $10 \mathrm{~mm}$-Tris $\cdot \mathrm{HCl}(\mathrm{pH} 7 \cdot 5)$. Subsequent purification of the phage particles by density gradient centrifugation and extraction of DNA with phenol were performed as described in the preceding paper (Jackson et al., 1978). The specific radioactivity of 222 DNA prepared by this procedure was $1 \times 10^{5}$ to $2 \times 10^{5} \mathrm{cts} / \mathrm{min}$ per $\mu \mathrm{g}$ DNA. 


\section{(e) Preparation of P22 [32P]DNA}

P22 $\mathrm{cl-7}$ was used to infect S. typhimurium LT2 strain 18 in a low-phosphate medium (Botstein, 1968) to which carrier-free $\mathrm{H}_{3}{ }^{32} \mathrm{PO}_{4}$ (New England Nuclear) was added at the time of infection to $10 \mu \mathrm{Ci} / \mathrm{ml}$. The resulting phage lysate was purified and DNA extracted as described above. Specific radioactivity of this DNA was approx. $3 \times 10^{5} \mathrm{cts} / \mathrm{min}$ per $\mu \mathrm{g}$ DNA.

\section{(f) EcoRI endonuclease cleavage}

DNA was digested with $E c o$ RI as described in the preceding paper (Jackson et al., 1978).

\section{(g) Agarose gel electrophoresis}

DNA molecules were separated by electrophoresis in cylindrical agarose gels as described in the preceding paper (Jackson et al., 1978).

Slab gel electrophoresis was performed by the method of DeLeys \& Jackson (1976). The electrophoresis buffer was $40 \mathrm{~mm}$-Tris, $5 \mathrm{~mm}$-sodium acetate, $1 \mathrm{mm-EDTA}$ (adjusted to $\mathrm{pH} 8.2$ with acetic acid). Agarose (Seakem) was made $0.7 \%(\mathrm{w} / \mathrm{v})$ in electrophoresis buffer, liquified by heating, and poured to form $24 \mathrm{~cm} \times 13 \mathrm{~cm} \times 0.45 \mathrm{~cm}$ slab gels. Samples were made $2 \cdot 5 \%(\mathrm{w} / \mathrm{v})$ Ficoll 400 (Pharmacia), and run into the gel at $180 \mathrm{~V}$ for $2 \mathrm{~min}$. The gels were then run at $30 \mathrm{~V}(20 \mathrm{~mA})$ for $15 \mathrm{~h}$ at room temperature. Buffer was circulated between the upper and lower chambers to maintain constant $\mathrm{pH}$.

The gels were stained for $45 \mathrm{~min}$ in ethidium bromide $(1 \mu \mathrm{g} / \mathrm{ml}$ in water $)$. DNA bands were visualized by the fluorescence of bound ethidium bromide upon illumination of the gel on a long-wave ultraviolet light source (C50 transilluminator, Ultraviolet Products). Gels were photographed on this light source using a Crown Graphic camera, Kodak Pan-X film, a u.v. filter (Ultraviolet Products) and either a Kodak number 25 or a number 9 Wratten gelatin filter. The Wratten number 9 filter was used to photograph gels for densitometric analysis, and a Kodak photographic step tablet (no. IA, O.D. range 0.05 to 3.05) was included in the photograph to confirm the linear film response under these conditions.

\section{(h) Quantitation of DNA mass per band in agarose gel}

\section{(i) Radioactivity determination}

$\left[{ }^{3} \mathrm{H}\right] \mathrm{DNA}$ or [ $\left.{ }^{32} \mathrm{P}\right] \mathrm{DNA}$ fragments were electrophoresed in agarose gels and stained with ethidium bromide. A gel segment containing a band was cut out with a razor blade and placed in a small glass vial for scintillation counting. Samples containing $\left[{ }^{3} \mathrm{H}\right] \mathrm{DNA}$ were covered with $2 \mathrm{ml}$ of Aquasol (New England Nuclear), agitated at $37^{\circ} \mathrm{C}$ for 18 to $24 \mathrm{~h}$, and counted in a Nuclear Chicago mark II scintillation spectrometer (DeVries et al., 1976). Samples containing [ $\left.{ }^{32} \mathrm{P}\right] \mathrm{DNA}$ were covered with $0.2 \mathrm{ml}$ water, and Chèrenkov radiation was counted in the scintillation spectrometer.

\section{(ii) Densitometric determination}

Images of DNA bands on photographic negatives following agarose slab gel electrophoresis were traced on a Joyce-Loebl microdensitometer. Areas under the peaks on the traces were measured using a Numonics Graphics calculator.

\section{(i) DNA hybridization}

\section{(i) Isolation of P22 EcoRI fragments}

A total of $100 \mu \mathrm{g}{ }^{32} \mathrm{P}$ or ${ }^{3} \mathrm{H}$-labeled P22 DNA was cleaved with $E c o$ RI, and fragments were separated by electrophoresis at $60 \mathrm{~V}$ for $14 \mathrm{~h}$ at $25^{\circ} \mathrm{C}$ in a $0.7 \%$ agarose slab gel $(24 \mathrm{~cm} \times 14 \mathrm{~cm} \times 0.6 \mathrm{~cm})$. Bands were cut from the gel, and the gel slices were extruded through a syringe with no needle, then through a 20 -gauge needle and finally through a 25-gauge needle. About $15 \mathrm{ml}$ of electrophoresis buffer wus added, and the DNA was eluted over $14 \mathrm{~h}$ at $4^{\circ} \mathrm{C}$. The agarose particles were pelleted by centrifugation in a Beckman 50Ti rotor at $30,000 \mathrm{revs} / \mathrm{min}$ for $2 \mathrm{~h}$ at $4^{\circ} \mathrm{C}$. The supernatant was removed and the DNA concentrated by precipitation with ethanol. The final yield of a fragment was usually about $50 \%$. Each fragment preparation was assayed for contamination with other fragments by mixing the labeled fragment with an EcoRI digest of unlabeled P22 DNA, and 
separating the cleavage fragments by agarose gel electrophoresis. Each band was cut from the gels, and the amount of radioactive isotope in each slice was counted as described above.

\section{(ii) IIybridization}

Hybridization of $\left[{ }^{3} \mathrm{H}\right]$ DNA to DNA fragments immobilized on nitrocellulose filters was performed by the method of Denhardt (1966).

A portion $\left(0.025 \mathrm{pmol}\right.$ ) of unlabeled (or ${ }^{32} \mathrm{P}$-labeled) fragment was denatured in alkali, fixed to 13-mm Schleicher and Schuell type BA85 nitrocellulose filters and preincubated for $6 \mathrm{~h}$ at $65^{\circ} \mathrm{C}$ in $0.02 \%$ each of Ficoll 400 , polyvinylpyrrolidone, and bovine albumin in $3 \times \mathrm{SSC}$ (SSC is $0.15 \mathrm{M}-\mathrm{NaCl}, 0.015 \mathrm{M}$-sodium citrate). ${ }^{3} \mathrm{HI}$-labeled DNA was denatured and fragmented by boiling for $40 \mathrm{~min}$ in $0.2 \mathrm{M}-\mathrm{NaOH}$. $0.005 \mathrm{pmol}{ }^{3} \mathrm{H}$-labeled denatured, broken, fragment was incubated with a DNA filter in $0.6 \mathrm{ml}$ of the same solution used for the preincubation. After $44 \mathrm{~h}$ at $65^{\circ} \mathrm{C}$, filters were removed, washed, dried and counted. Each annealing reaction was performed in triplicate. The rate of annealing is slow at the DNA concentrations used. Hybridization was measured as a function of time in control experiments using P22 DNA at the same molar concentration described ahove. Of the total labeled P22 DNA, 50\% was bound to the filter at $44 \mathrm{~h}$.

\section{(j) Nomenclature}

Bands appearing following agarose gel electrophoresis of EcoRI digests of P22 insertion and deletion mutant DNA are assigned letter designations according to the convention outlined in tho proceding paper (Jackson et al., 1978). By this system the same fragment forms P22 Tc-10 band $\epsilon$ and P22 bpl band $\alpha$. Bands in a mutant EcoRI digest which are not found in a P22 wild-type digest are assigned Greek letters in order of increasing elentrophnretic mobility withmit regard to whather a given fragment was produced by two EcoRI cleavages or was derived from EcoRI cleavage of an end of a mature linear chromosome.

\section{Results}

(a) EcoRI cleavage fragments of P22 mature chromosomes

When circularly permuted P22 chromosomes are cleaved with restriction endonuclease $E c o R I$, and the cleavage products are separated by electrophoresis on agarose gels, eight bands are seen (Fig. 1(a)) (Helling et al., 1974; Jackson et al., 1978). Two of these bands, A and D, are unusual. Band A contains fragments which are hetero. geneous in size, since the band is wide and diffuse. Band D is stained less intensely than the faster migrating band $\mathrm{E}$, and so is present in lower molar yield than band $\mathrm{E}$. It seemed likely that these unusual bands are a consequence of the limited circular permutation of P22 mature DNA, since no such anomaly is seen among the EcoRI cleavage products of $\lambda$ DNA (Thomas \& Davis, 1975).

The unusual features of the P22 EcoRI digest which can be seen by inspection of the gel in Figure 1(a) were studied in more detail. The lengths of fragments comprising P22 band $A$ were measured in electron micrographs (see Jackson et al., 1978). The lengths of the fragments correspond to a range of molecular weights from about $10 \times 10^{6}$ to $13 \times 10^{6}$. This result confirms the expectation that the fragments in band $A$ are heterogeneous in size.

The molecular weights of the P22 EcoRI fragments have been determined and are shown in Table 1. These values were used to determine the molar yield of P22 EcoRI fragments. The molar yield of each band appearing after agarose gel electrophoresis was measured by three different methods. The results are shown in Table 2. Results of parallel determinations using $\lambda E c o R I$ fragments are included for comparison. As expected, the molar yield of P22 fragment D is low; there are only about one 


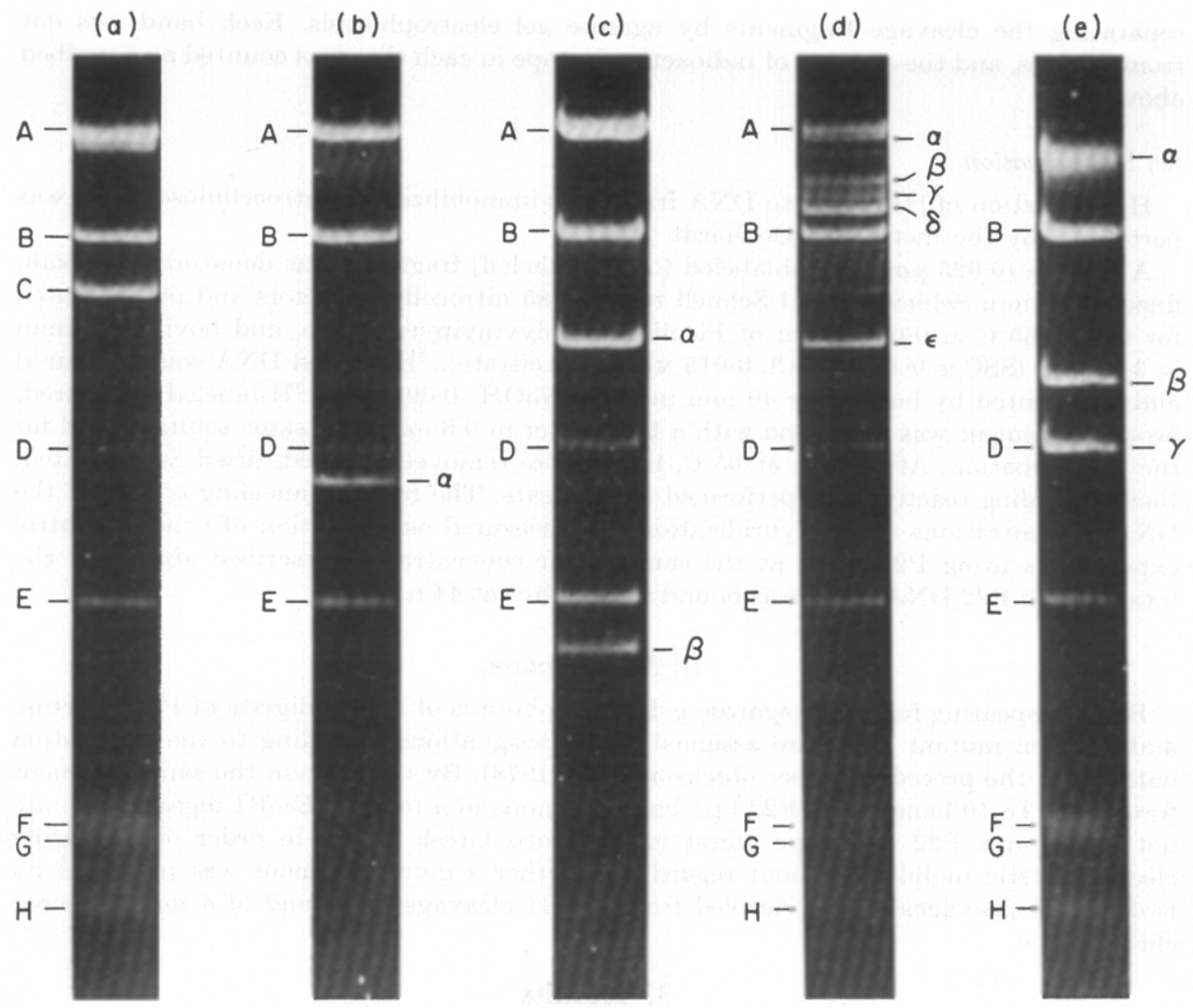

Fra. 1. Agarose gel electrophoresis of EcoRI digests of P22 and P22 deletion and insertion DNAs (a) P22 c1-7 DNA (wild type); (b) P22 bp5 DNA (16\% net deletion); (c) P22 bp1 DNA (7\% net deletion); (d) P22 Tc-10 DNA (20\% insertion); (e) P22 pro-3 DNA (3\% net insertion).

DNA was isolated from mature phage particles and cleaved to completion with endoR $\cdot E$ coRI. Eleotrophoresis in $0.7 \%$ agarose gels was performod and tho gels stainod in othidium bromide and photographed while illuminated with u.v. light (see Materials and Methods). P22 bands are labeled by capital letters in order of increasing electrophoretic mobility. Bands appearing as products of EcoRI cleavage of deletion or insertion DNAs are labeled by Greek letters.

third as many molecules of fragment $\mathrm{D}$ as of fragment $\mathrm{C}$. In addition, the molar yields of two other fragments, $\mathrm{A}$ and $\mathrm{B}$, are significantly less than the yield of $\mathrm{C}$. Thus the P22 fragments appearing after EcoRI cleavage are not present in equimolar yield. In contrast, the six $\lambda E c o R I$ fragments are present in equimolar amounts as expected (Table 2; Thomas \& Davis, 1975).

(b) Positions of molecular ends define a physical map of headful maturation events

When a concatemer is cleaved during P22 DNA encapsulation, the products are a population of molecules whose ends fall at a variety of locations relative to restriction enzyme cleavage sites. Restriction endonuclease digestion of these different permuted molecules will generate different sets of fragments. In a population of circularly permuted DNA molecules, the nucleotide sequence between two adjacent restriction enzyme cleavage sites will sometimes be intact, and will sometimes be 


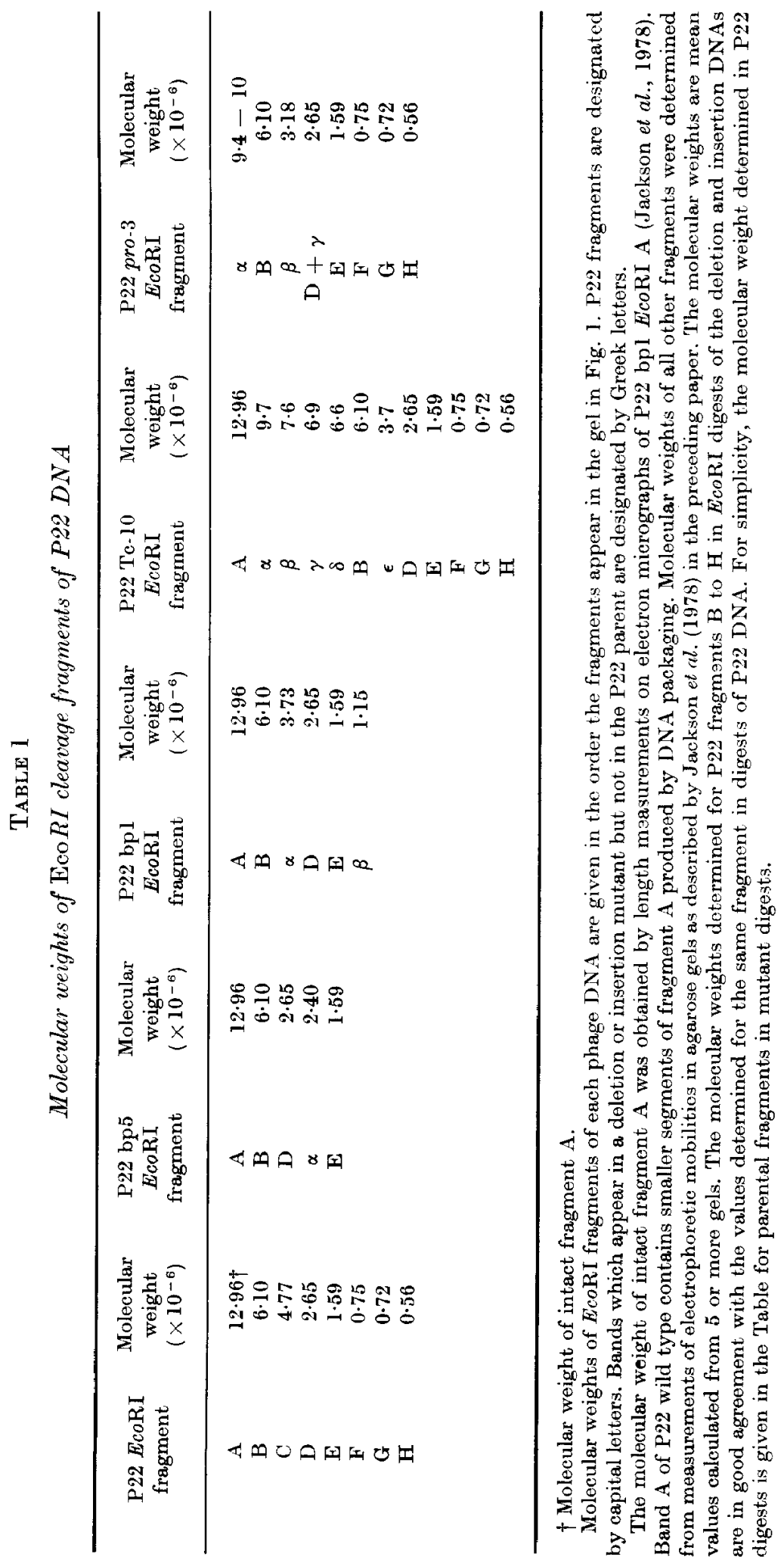


Table 2

Molar yields of $\lambda$, P22, P22 pro-3, and P22 Tc-10 EcoRI cleavage fragments

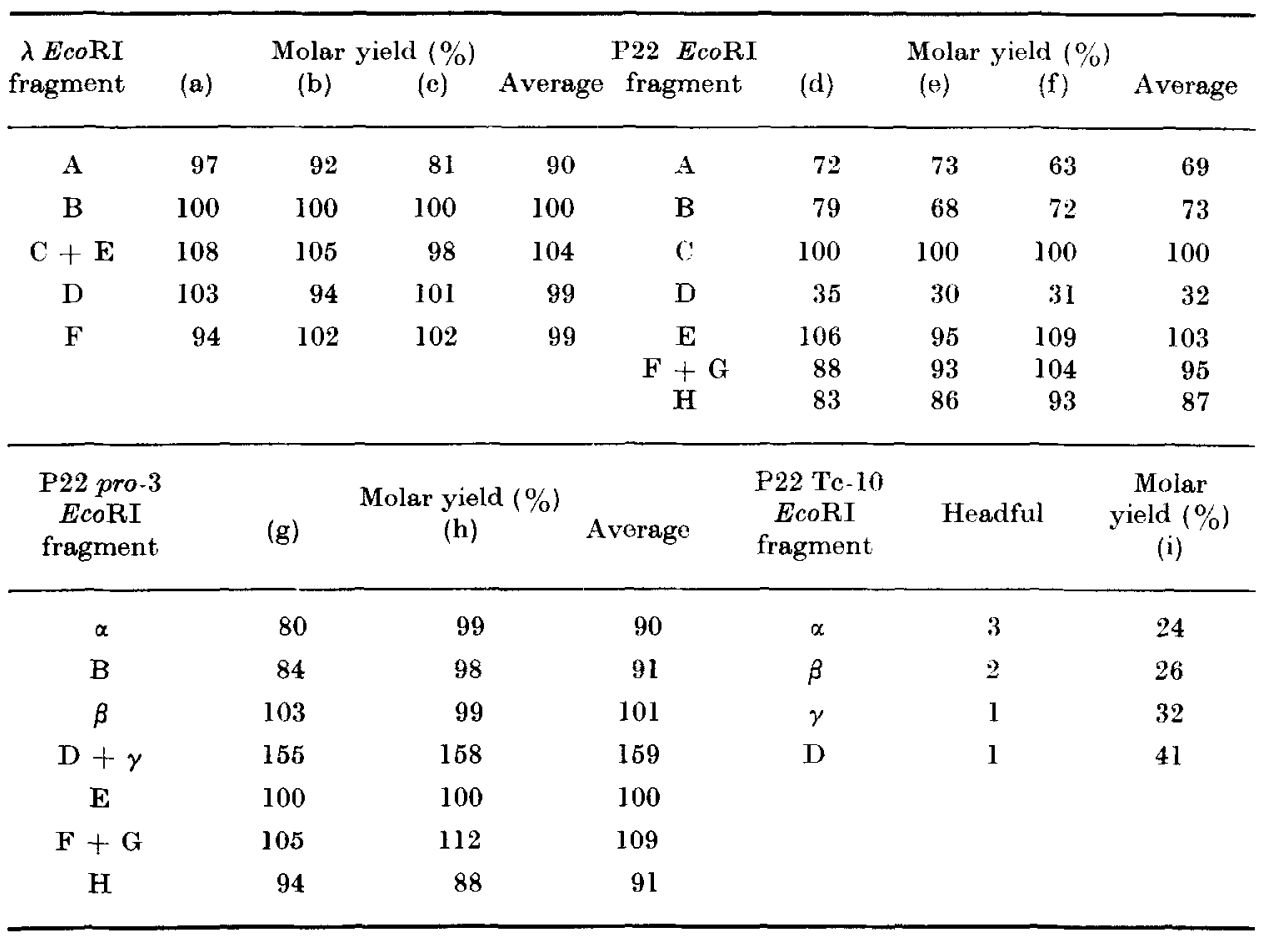

P22 and $\lambda$ DNAs were cleaved with EcoRI and fragments separated by agarose gel electrophoresis as described in Materials and Methods. The amount of DNA in each band was measured

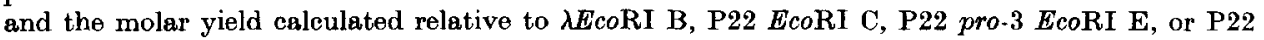
Te-10 EcoRI E. Amount of DNA in a band was measured by 1 of 3 different methods.

(a), (d) and (h) Scintillation counting of $\left[{ }^{3} \mathrm{H}\right] \mathrm{DNA}$.

(b) and (e) Scintillation counting of [32P]DNA.

(c), (f), (g) and (i) Densitometric measurement of band image on a photographic negative.

Molar yield calculations use the molecular weights given by Thomas \& Davis (1975) for $\lambda E c o R I$ fragments and molecular weights for P22 and P22 mutant EcoRI fragments given in Table 1. Values in each column are mean results from 10 gels ((a) and (b)); 3 gels (c); 24 gels ((d) and (e)); 3 gels ((f), (g), (h) and (i)).

The slightly high molar yield of P22 Tc-10 EcoRI D is probably due to contamination with heterogeneous short segments of $E c o R I$ A from the second headful and fragments of $E$ coRI $\delta$ from the fourth headful, both of which have calculated mean molecular weights similar to EcoRI D.

interrupted by molecular ends. If molecular ends preferentially fall in one region of the genome, some restriction fragments will be more frequently lost than others. Therefore, an EroRI digest of a collection of P22 linears might contain some EroRI fragments in low yield. The digest will also include a variety of fragments from the ends of linear molecules and, if enough linears have the same ends, such fragments will form visible bands in gels.

To determine precisely how molecular ends affect the bands obtained on gel electrophoresis of an EcoRI digest of P22 DNA, we compared these bands with those obtained from EcoRI digests of P22 deletion and insertion mutant DNAs. These mutations increase or decrease the genome size but do not alter headful length or the 
position at which packaging begins or the direction in which sequential packaging proceeds (Tye et al., 1974a,b). In such deletion or insertion mutants, the ends of mature linear DNA molecules will be at new positions relative to EcoRI sites. By comparing the mutant and wild-type digests we determined what hands are derived from molecular ends, and from the molecular weights of the end fragments, we placed the maturation cleavages on the EcoRI map of each mutant DNA. From these various maturation cleavage maps we could locate the specific site of packaging initiation and the direction of sequential packaging relative to the $E$ coRI site map. The physical map of maturation cleavages during encapsulation of wild-type P22 DNA summarizes our conclusions (Fig. 2). From the results of the preceding paper (Jackson et al., 1978) we obtain the circular order of EcoRI fragments ... BECGFHA.... The comparisons of wild type and deletion and insertion mutant EcoRI digests confirm that the complete map of P22 DNA is a circular assembly of these seven fragments (Fig. 2). The specific packaging initiation site (for which we propose the new genetic term pac) is located in fragment $A, 4 \cdot 1 \times 10^{3}$ base-pairs clockwise (Fig. 2) from EcoRI cleavage site 1. Sequential packaging proceeds in the counterclockwise direction relative to the fragment map in Figure 2. Although for any single mutant digest, alternative positions for pac or the reverse direction of sequential encapsulation might be congruent with the fragments observed, only the scheme of Figure 2 accounts for all the fragments seen in the four different mutant $E c o$ RI digests as well as the digest of wild-type DNA. The analysis of the mutant digests is presented in detail below.

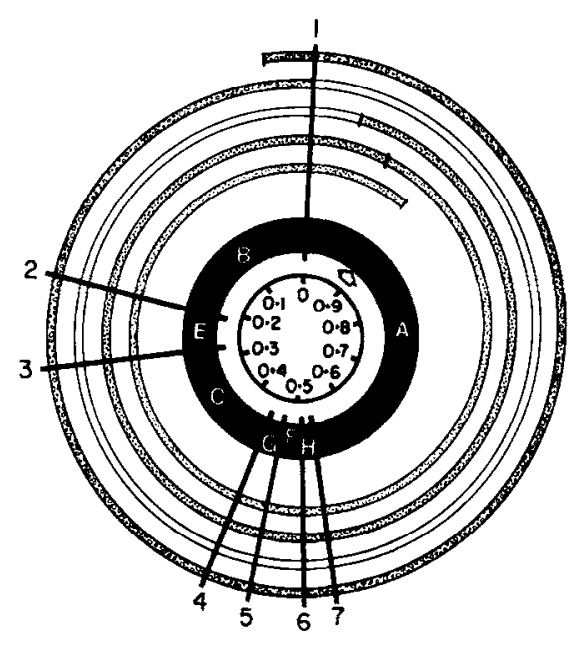

Fia. 2. Map of EcoRI cleavage sites and headful maturation cleavages in P22 DNA. The circular EcoRI cleavage map of P22 DNA is diagrammed to scale. EcoRI fragments are lettered. The numbered EcoRI cleavage sites are shown as radii of the circle. A segment of a concatemer is shown diagrammatically as a spiral wound around the circular fragment map. The concatemer may extend beyond the length in the Figure. Headful encepsulation of DNA begins at the packaging initiation site ( $p a c)$ in fragment $A$ shown by arrow (4100 buse-puirs from EcoRI site 1) and sequential headfuls proceed along the concatemer in thecounterclockwise direction relative to the fragment map. In the Figure the length of one headful is $103 \%$ of the contour length of the fragment map. Positions of headful cleavage events producing mature linear molecules are to, scale (polar co-ordinates). The lengths of headfuls can vary slightly (diagrams not shown). Physical map co-ordinates are shown on the inner circle. Fragment D is the short segment of EcoRI A in tho first headful defined by EcoRI cleavage site 1 and $p a c$. 


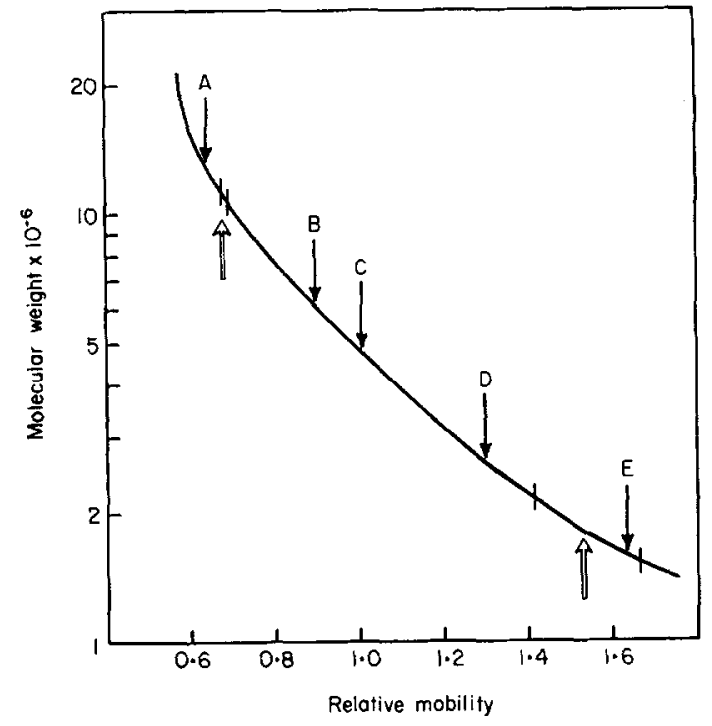

FIG. 3. Separation of fragments in an EcoRI digest of P22 DNA by agarose gel electrophoresis. The standard curve relating molecular weight to electrophoretic mobility in $0.7 \%$ agarose gels was obtained by measuring mobility of DNA molecules of known size under the conditions of electrophoresis defined in the preceding paper (Jackson et al,, 1978). Mobility of intact P22 fragments $A$ through $E$ are indicated above the curve by filled arrows. Molecular weights of the larger and smaller pieces of EcoRI A produced by the maturation cleavage between the first and second headfuls were calculated assuming $103 \%$ headful length. Their predicted relative mobilities are shown by open arrows below the curve. Vertical bars crossing the curve show the change in position for each of these segments of EcoRI A if headful size were $102 \%$ or $104 \%$. A $1 \%$ variation in headful size results in a substantial change in mobility of the small piece of EcoRI A but only a small change in mobility of the larger piece of $A$ for 3 resons: (1) a variation in headful size of $\pm 1 \%$ of the complete P22 genome is a large proportion of the size of the shorter segment of EcoRI A but a much smaller fraction of the size of the larger segment of EcoRI A; (2) relative mobility of DNA fragments is an approximately linear function of the logarithm of the molecular weight, thus causing larger mobility changes for a unit change in molecular weight for a small fragment than for a large one; (3) the correlation between log molecular weight and relative mobility for linear DNA fragments in $0.7 \%$ agarose gels becomes steeply non-linear above a molecular weight of $6 \times 10^{6}$ to $7 \times 10^{6}$ (Helling et al., 1974), so that differences in mobility due to different molecular sizes are small for large DNA fragments.

\section{(c) EcoRI cleavage site maps of the P22 Tc-10 insertion and its deletion derivatives}

When EcoRI cleavage products of deletion and insertion mutant DNAs were studied, quite different sets of bands were seen for each mutant digest (Fig. I). In order to determine which fragments are derived from molecular ends, EcoRI cleavage site maps were prepared for each mutant. The physical size and genetic location of each deletion or insertion has been determined by Tye et al. (1974a). This information, together with the correlation of the EcoRI site map with the genetic map described in the preceding paper, facilitated mapping EcoRI sites on the mutant genomes. The deletion mutants bpl and bp5 are both derived from the insertion mutant Tc-10, so the EcoRI cleavage site maps of these three chromosomes are related. 'The fourth mutant, the insertion strain $\mathrm{P} 22$ pro-3, is not related to the other three, and its $E c o$ RI cleavage site map is described later.

The DNA of specialized transducing phage P22 Tc-10 contains a large $\left(8.3 \times 10^{3}\right.$ base-pairs) insertion of foreign DNA (Tye et al., 1974a). The insertion includes genes which determine resistance to the antibiotic tetracycline. Since the $t e t^{\mathrm{R}}$ insertion is 
about $20 \%$ the length of a complete set of P22 genes, and a $\mathrm{P} 22$ phage head packages a headful of DNA equal in length to about 102 to $103 \%$ of one complete set of P22 genes, each particle of P22 Tc-10 contains an incomplete set of phage genes. Chan (1974) selected plaque-forming revertants of the defective P22 Tc-10. Two of these revertants, $\mathrm{P} 22 \mathrm{bp} 5$ and $\mathrm{P} 22 \mathrm{bpl}$, were shown to carry large deletions which remove part of the tet ${ }^{\mathrm{R}}$ insertion and some non-essential phage genes. Each of the deletions reduces the size of the genome so that a complete set of essential P22 genes can fit into one phage head. The size of each deletion exceeds the size of the $t e t^{\mathrm{R}}$ insertion. Tye et al. (1974a) showed that the P22 bpl genome, which is $95 \%$ of the length of wild type, was generated by a $10 \cdot 4 \times 10^{3}$ base-pair deletion of the P22 Tc-10 parent. Similarly, P22 bp5, $86 \%$ as long as wild type, was produced by a $14 \cdot 1 \times 10^{3}$ basepair deletion in P22 Tc-10.

\section{(i) EcoRI cleavage sites in P22 bp5 DNA}

EcoRI cleavage products of linear P22 bp5 DNA were separated by agarose gel electrophoresis (Fig. 1(b)). The P22 bp5 digest lacks P22 EcoRI bands C, F, G and H. Therefore, the deletion removes P22 EcoRI sites 4, 5 and 6 (see Figs 2 and $4(\mathrm{~d})$ ). Since there is only one new fragment ( $\alpha$ in Fig. $1(b)$ ), no EcoRI site is present in the short piece of the $t e t^{\mathrm{R}}$ insertion retained in P22 bp5. The new fragment $\alpha$ is therefore generated by cleavage at P22 EcoRI sites 3 and 7 . The sum of the molecular weights of the P22 bp5 fragments (less fragment D) equals $23.1 \times 10^{6}, 84 \%$ of the sum of the fragments of wild-type DNA. This genome length is in good agreement with the value of $86 \%$ obtained by Tye et al. (1974b) from heteroduplex measurements. The complete EcoRI cleavage site map of the P22 bp5 chromosome is shown in Figure 5.

\section{(ii) EcoRI cleavage sites in P22 bp1 $D N A$}

The EcoRI fragments of mature P22 bpl DNA are shown in Figure 1(c). The digest lacks P22 fragments C, F, G and H, so the deletion removes P22 EcoRI sites 4.5 and 6 . Two new fragments appear, so the portion of the $t e t^{\mathrm{R}}$ insertion remaining in P22 bpl bears an EcoRI cleavage site. Since the new fragment $\alpha$ is found in the P22 Tc-10 parent, but $\beta$ is not (see below), the orientation of these two fragments must be that shown in Figure 4(f). The cleavage site map of $\mathrm{P} 22 \mathrm{bpl}$ is given in Figure 6. The sum of the molecular weights of the P22 bpl EcoRI pieces (excluding fragment D) is $25 \cdot 5 \times 10^{6}$, or $93 \%$ of P22 wild type. This measurement of the size of the P22 bpl genome agrees well with the value of $95 \%$ for this mutant genome calculated from heteroduplex analysis (Tye et al., 1974a; Chan \& Botstein, 1976).

\section{(iii) EcoRI cleavage sites in P22 Tc-10 DNA}

P22 Tc-10, which carries the $t^{\mathrm{R}}$ insertion, has no deletion of P22 sequences (Tye of $a l ., 1974 b)$. Therefore the insertion will cause only one wild-type EcoRI fragment to be missing from the Tc-10 EcoRI digest. Figure 1(d) shows that P22 EcoRI fragment $\mathrm{C}$ is the only fragment missing from the digest. The $t e t^{\mathrm{R}}$ element is therefore inserted in fragment $C$ between P22 EcoRI sites 3 and 4 in P22 Tc-10.

The P22 Tc-10 digest also contains a number of new bands not produced by EcoRI cleavage of wild-type P22. P22 Tc-10 band $\epsilon$ is identical to band $\propto$ of P22 bpI and therefore is derived from EcoRI cleavage at P22 site 3 and an EcoRI site in the $t e t^{\mathrm{R}}$ insertion. Band $\delta$ is produced by cleavage at the EcoRI site in the $t e t^{\mathrm{R}}$ 
(a)

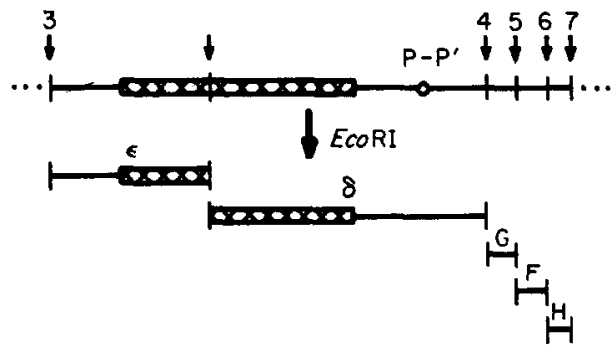

(c)

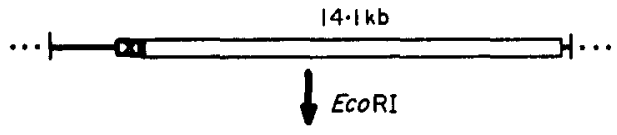

(d)

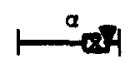

(e)

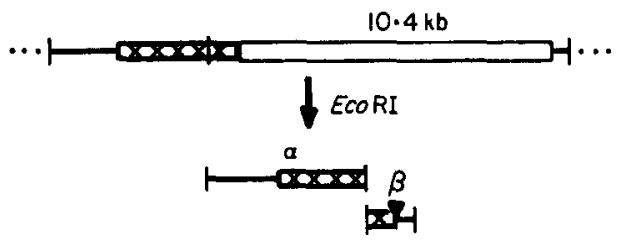

Fig. 4. EcoRI cleavage site maps of the Tc-10 tet $^{\mathrm{R}}$ insertion and the bpl and bp5 deletions between P22 EcoRI sites 3 and 7.

Positions of EcoRI cleavage sites (Jackson et al., 1978) are to scale. Cleavage site numbers correspond to the P22 wild-type cleavage map (Fig. 2). kb, 1000 bases.

(a) Physical gene map to scale of P22 Tc-10 DNA between P22 EcoRI cleavage sites 3 and 7. Size of DNA segment shown is $18.7 \times 10^{3}$ bases. Physical co-ordinates of the phage attachment site (O) relative to the tet $t^{\mathrm{R}}$ insertion from the data of Chan \& Botstein (1976). $(\overline{\mathrm{X}} \times \overline{\mathrm{X}}$ ) Indicates the tet $t^{\mathrm{R}}$ insertion. Size of the insertion is $20 \%$ of the size of the complete P22 genome. P.P' is located $2.5 \times 10^{3}$ bases from the right end of the tet ${ }^{\mathrm{R}}$ insertion and $13.5 \times 10^{3}$ bases from $E c o R I$ site 3. Gene int is to the right of P-P' but left of site 7, and gene erf is to the right of site 6 .

(b) P22 Te-10 EcoRI fragments derivod from the region of the chromosome diagrammed in (a).

(c) Physical gene map of P22 bp5 DNA between P22 EcoRI cleavage sites 3 and 7. The open bar represents the deletion. Size of the deletion is calculated from the data in Table 2 .

(d) P22 bp5 EcoRI fragment derived from the region of the chromosome diagrammed in (c). (V) Represents the site of the deletion.

(e) Physical gene map of P22 bpl DNA between P22 EcoRI cleavage sites 3 and 7. The open bar represents the deletion. Size of the deletion is calculated from the data in Table 2.

(f) P22 bpl EcoRI fragments dorived from the region of the chromosome diagrammed in (e). P22 bpl fragment $\alpha$ is the same as $\mathrm{Tc}$-10 fragment $\epsilon$.

insertion and at P22 EcoRI sitc 4 (Fig. 4(a) and (b)). The sum of the molecular weights of the two fragments $\delta$ and $\epsilon$ is $10.3 \times 10^{6}$ (Table 1), in good agreement with the value $10.5 \times 10^{6}$ expected from a $20 \%$ insertion in fragment $C$. The other new P22 Tc-10 bands $\alpha, \beta$ and $\gamma$ are a consequence of headful packaging of the oversize Tc-10 DNA (see below). Therefore Tc-10 contains one more EcoRI cleavage site than wild type. This additional $E c o R I$ site is located in the $t^{\mathrm{R}}{ }^{\mathrm{R}}$ insertion which occurred in P22 fragment C (Figs 4(a) and 7).

\section{(d) The pac site lies in EcoRI fragment $A$}

In the EcoRI digests of Tc-10, bpl and bp5 mutant DNAs, band $A$ is sharp and band $D$ is present in low yield (Fig. 1 (b) to (d)). These results led us to propose that 
both fragment $\mathrm{D}$ and the heterogeneous smaller fragments in band $\mathrm{A}$ of a wild-type digest are produced by EcoRI cleavage near ends of linear molecules. Since the only molecular end which falls at the same position on wild type and mutant genomes is the end of the first chromosome encapsulated at pac, we postulated that EcoRI cleavage of the first DNA headful of all these phages produces fragment $D$. Therefore pac would be located $4 \cdot 1 \times 10^{3}$ bases (the length of fragment D) from an EcoRI cleavage site. All other molecular ends will be at different positions in each mutant compared to wild type. Since all three mutants have only one size of fragment in band $A$, we conclude that in wild type the heterogeneous smaller fragments are produced by $E c o$ RI cleavage of linear molecules having ends at varying positions within fragment $A$ (see Fig. 2). In the Tc-10 insertion phage and the bpl and bp5 deletion mutants, the size of the genome has increased or decreased while the length of a headful is unchanged, so that ends of mature linear molecules no longer fall primarily in fragment A (see Figs 5 to 7 ). The position of wild-type permuted ends in each sequential headful moves only $3 \%$ along the genome, and so these ends fall in the vicinity of pac. Therefore, the proposal that permuted ends of wild-type molecules fall primarily in EcoRI A suggests that pac should also lie in fragment A.

The proposal that fragment $\mathrm{D}$ is a subset of the nucleotide sequences of P22 $E c o R I$ A was tested directly by measuring hybridization between fragment D and each of the other P22 EcoRI fragments. Fragment D hybridizes to fragment A but not to any of the other P22 EcoRI fragments (Table 3). Fragment D is therefore identical to a nucleotide sequence contained in fragment $A$, and this sequence is found in no other region of the $\mathrm{P} 22$ genome.

Since fragment $\mathrm{D}$ is a segment of fragment A, pac should be between EcoRI sites 1 and 7 , and within $4.1 \times 10^{3}$ bases (10\% of the P22 genome) of one of the sites. The

\section{Table 3}

Hybridization between EcoRI fragments of P22 DNA

\begin{tabular}{|c|c|c|c|c|c|}
\hline \multicolumn{2}{|c|}{ DNA on filter } & \multicolumn{2}{|c|}{$\left[{ }^{3} \mathrm{H}\right] \mathrm{DNA}$ in solution } & \multicolumn{2}{|c|}{ Hybridization (\%) } \\
\hline $\begin{array}{l}\text { P22 } E c o R I \\
\text { fragment }\end{array}$ & $\mu \mathrm{g}$ & $\begin{array}{l}\text { P22 EcoRI } \\
\text { fragment }\end{array}$ & $\mu \mathrm{g}$ & (a) & (b) \\
\hline$A$ & $0 \cdot 32$ & $A$ & 0.064 & 52 & 54 \\
\hline A & $0 \cdot 32$ & $\mathrm{D}$ & $0 \cdot 013$ & 50 & 52 \\
\hline A & $0 \cdot 32$ & $\mathrm{E}$ & 0.008 & 7 & 7 \\
\hline $\mathbf{E}$ & 0.04 & $\mathrm{D}$ & 0.013 & 14 & 15 \\
\hline
\end{tabular}

The EcoRI cleavage fragments used were prepared from P22 wild-type DNA. Specific activity of the $\left[{ }^{3} \mathrm{H}\right] \mathrm{DNA}$ is $1.0 \times 10^{5} \mathrm{ets} / \mathrm{min}$ per $\mu \mathrm{g}$. A total of 0.025 pmol of a fragment was fixed to a filter and incubated with $0.005 \mathrm{pmol}{ }^{3} \mathrm{H}$-labeled fragments in solution. Blank filters included in each hybridization vial bound $0.5 \%$ of the total ${ }^{3} \mathrm{H}$-labeled DNA. Percentage hybridization is the ratio of the ${ }^{3} \mathrm{H}$-labeled DNA hybridized to the total ${ }^{3} \mathrm{H}$-labeled DNA. The values given are the average of 3 annealing reactions performed in parallel, and (a) and (b) are results of 2 independent hybridization experiments.

The EcoRI A preparation fixed to the filter contains $2 \%(0.006 \mu \mathrm{g}) E c o R I E$, and the EcoRI E preparation bound to the filter contains $3 \%(0.001 \mu \mathrm{g}) E$ coRI D. In addition, $5 \%$ by weight of the $\left[{ }^{3} \mathrm{H}\right] E c o R I D$ preparation is EcoRI E. Therefore, the apparent low level of annealing of [ $\left.{ }^{3} \mathrm{H}\right] \mathrm{E}$ to $\mathrm{A}$, or $\left[{ }^{3} \mathrm{H}\right] \mathrm{D}$ to $\mathrm{E}$ is due to hybridization of contaminating fragments. When each of the $\mathrm{P22}$ EcoRI fragments A, B, C and E was annealed with the same fragment on the filter, about 50\% of the input $\left[{ }^{3} \mathrm{H}\right] \mathrm{DNA}$ hybridized to the filter. When EcoRI [ $\left.{ }^{3} \mathrm{H}\right] \mathrm{D}$ preparations were incubated with each of these fragments fixed to filters, $15 \%$ or less of the ${ }^{3} \mathrm{H}$-labeled DNA bound to the filter (data not shown for all fragments). 


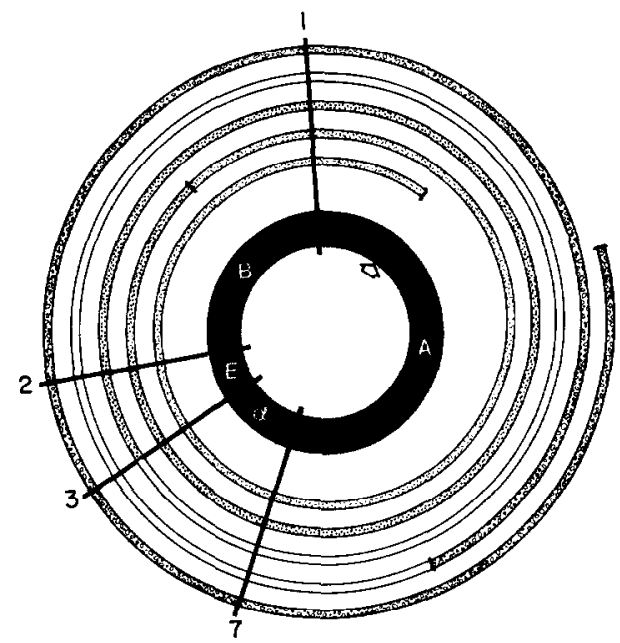

FIG. 5. Map of EcoRI cleavage sites and headful maturation cleavages in P22 bp5 DNA.

The circular EcoRI cleavage map of P22 bp5 DNA is diagrammed to scale. The P22 bp5 genome is $84 \%$ the size of P22 wild-type (Fig. 2). Symbols are as in Fig. 2. The model for P22 DNA maturation described in Fig. 2. was used to predict the positions of headful cleavages shown.

fact that band $B$ is found in low yield in the wild-type digest suggests that some ends of wild-type linears fall within B and therefore that pac is nearer EcoRI site 1, and that sequential packaging proceeds in the counterclockwise direction (Fig. 2). The placement of fragment D at the EcoRI site 1 end of fragment A is further supported by the results of $S m a I$ restriction enzyme digestion of P22 DNA. SmaI cleaves P22 DNA twice. Both sites are located at the EcoRI site 1 end of fragment A at map coordinates 0.91 and 0.87 (R. J. Deans, unpublished experiments). Fragment D is cleaved once by SmaI, demonstrating that fragment D lies between EcoRI site I and co-ordinate 0.90 and includes the $S m a I$ site at 0.91 on the P22 physical map. Additional evidence to support the physical map of maturation events shown in Figure 2 comes from further study of $E c o$ RI digests of the insertion and deletion derivatives of P22 DNA.

\section{(e) Physical map of molecular ends of P22 bp5 DNA}

The consequences of headful packaging of P22 bp5 DNA in accordance with the scheme outlined above are diagrammed in Figure 5. Packaging begins at pac, as in wild-type DNA (Tye et al., 1974b), and proceeds sequentially without further site specificity in the counterclockwise direction. The size of the DNA headful cleaved from the concatemer is the same as in the case of wild-type phage (102 to $103 \%$ of one complete set of wild-type P22 genes). Figure 5 shows the calculated positions of headful clcavages of the P22 bp5 concatemer relative to EcoRI cleavage sites. EcoRI digestion of these P22 bp5 linear DNA molecules will produce fragment D in low molar yield as in wild type, since the site on the conca temer at which headful packaging initiates is not altered by the deletion. The diagram further shows that, in contrast to wild-type P22, fragment A is intact in early headfuls. The result of electrophoretic analysis of the EcoRI cleavage products of P22 bp5 is shown in Figure 1(b). Fragment $\mathrm{D}$ is found in low molar yield; band $\mathrm{A}$ is sharp and lacks the diffuse leading edge seen in EcoRI digests of P22 wild-type DNA. The diagram shows that third and 
fourth headfuls would yield medium-sized fragments of $A$, and a diffuse band is present in the region of the gel (between bands A and B) where these fragments should migrate. Fragments produced by EcoRI cleavage of linear molecules with ends falling between EcoRI sites 1 and 2 are not seen. The absence of these short fragments can be explained if the length of DNA in a headful varies slightly. If this small variation is large with respect to the size of the fragment derived from a molecu. lar end, the molecular weight distribution of the fragment would be heterogeneous and it would not form a visible band in gels. Figure 3 presents a detailed analysis of this point. Chan (1974) has independently proposed that P22 headful lengths are variable.

\section{(f) Physical map of molecular ends of P22 bp1 DNA}

The physical location of maturation cleavages of P22 bpI DNA was calculated from the postulates outlined above, and the results are shown diagrammatically in Figure 6. An EcoRI digest of the resulting linear DNA molecules would contain fragment $\mathrm{D}$ in low molar yield, since the specificity of initiation of a packaging sequence is unchanged. Molecular ends do not fall in fragment $A$, so heterogeneous shorter segments of $A$ should not appear in the digest. The fragments generated by EcoRI digestion of P22 bpl linear DNA support the model (Fig. 1(c)). Fragment D is found in low molar yield and band A lacks the diffuse leading edge seen in wild type. The fragments of the mature linear chromosomes corresponding to segments of $E c o$ RI fragment B will vary in size due to variation in the length of the headful packaged. Since these fragments are small, the small variation in headful size will be a large fraction of their length and consequently they will not appear as visible bands. The direction of sequential packaging must be counterclockwise as shown in Figure 6, since if packaging of bpl DNA began at the site indicated but proceeded sequentially in the clockwise direction, no intact fragment A would be found.

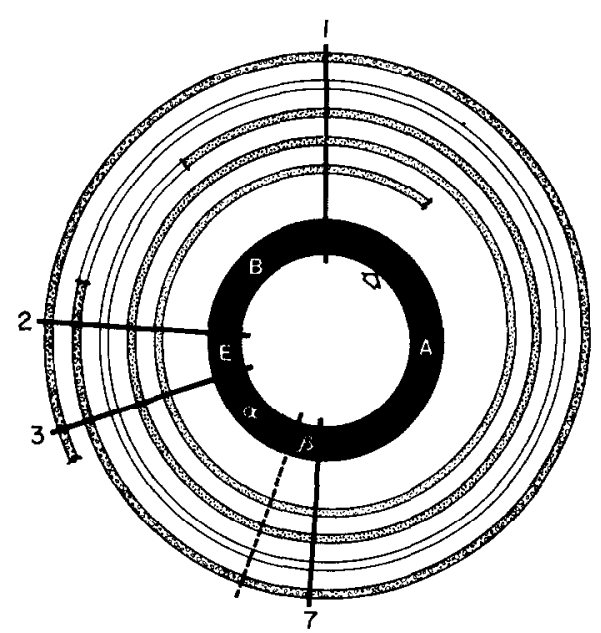

Fig. 6. Map of $E c o R I$ cleavage sites and headful maturation cleavages in P22 bpl DNA.

The circular EcoRI cleavage map of P22 bpl DNA is diagrammed to scale. The P22 bpl genome is $93 \%$ the size of P22 wild-type (Fig. 2). Symbols are as in Fig. 2. (-----) Designates the $E c o R I$ cleavage site in the remaining portion of the tet ${ }^{\mathrm{R}}$ insertion (see Fig. 4). The model for DNA maturation described in Fig. 2 was used to predict the positions of molecular ends relative to the EcoRI cleavage site map. 
(g) Physical location of molecular ends of P22 Tc-10 DNA

The headful packaging scheme applied to P22 Tc-10 predicts a complex set of bands following electrophoretic separation of EcoRI cleavage fragments (Fig. 7). Since packaging initiates at the normal site in fragment $A$, the ends of the chromosomes packaged in first headfuls will yield fragment D on $E c o R I$ cleavage. The first headful DNA molecule also produces a long piece of $A$. The second headful yields another long section of $A$, while one end of the third headful is a piece of $A$ only slightly shorter than intact P22 fragment A. All these three segments of A will appear as visible bands on agarose gels despite variation in headful length, since all these fragments are over about $M_{\mathrm{r}}=7 \times 10^{6}$ in length (see Fig. 3 for detailed explanation).

These predictions are confirmed in Figure $1(d)$. Fragment $D$ is present in low yield. Three new bands containing fragments smaller than EcoRI A but larger than any other EcoRI fragment appear. Band $\gamma$ is derived from one end of the first headful, $\beta$ from the second headful, and $\alpha$ from the third sequential headful. The molecular weights of these three fragments calculated from the diagram approximate those estimated from the mobility of the fragments in the gel (see Table 1 and the legend to Fig. 7). Intact fragment $A$ is found in low yield, since it derives only from the fourth sequential headful in a packaging sequence.

\section{(h) Positions of ends of linear DNA molecules relative to EcoRI sites in P22 pro-3 $D N A$}

An insertion mutant of P22 not derived from P22 Tc-10 also provides strong support for the packaging model of Figure 2. P22 pro-3 is a defective specialized

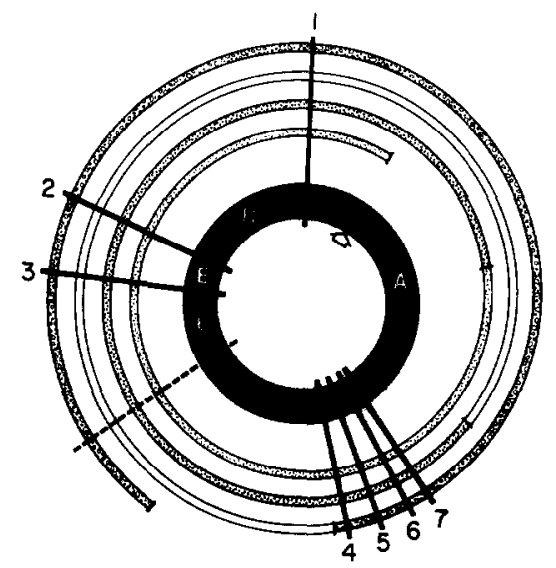

FIG. 7. Map of EcoRI cleavage sites and headful maturation cleavages in P22 Tc-10 DNA. The circular EcoRI cleavage map of P22 Tc-10 DNA is diagrammed to scale. The P22 Tc-10 genome including the tet ${ }^{\mathrm{R}}$ insertion is $120 \%$ the size of P22 wild-type (Fig. 2). Symbols are as in Fig. 2. (-- - D ) Designates the EcoRI cleavage site in the tet ${ }^{\mathbb{R}}$ insertion (see Fig. 4). The model for P22 DNA maturation described in Fig. 2 was used to predict the positions of molecular ends on the physical map of $E c o R I$ cleavage sites. If the ends of linear molecules were as shown, EcoRI digestion of DNA packaged in the first headful would generate fragments $D$ and $\gamma$ (predicted $M_{\mathrm{r}}=6 \cdot 1 \times 10^{6}$ ) in low yield; the second headful would produce fragment $\beta$ (predicted $M_{\mathrm{r}}=$ $\left.6.9 \times 10^{6}\right)$, the third would yield fragment $\alpha$ (predicted $\left.M_{\mathrm{r}}=11.1 \times 10^{6}\right)$, and only the linear DNA molecules from the fourth sequential headful would yield intact fragment $A$. 
transducing phage which arose by abnormal excision of a P22 prophage. This excision event generated a $6 \%$ insertion of bacterial genes and a $3 \%$ deletion of phage sequences, including part of the phage attachment site (Chan, 1974; Chan \& Botstein, 1976: .Jessop, 1976). The formation of P22 pro-3 is therefore analogous to formation of dgal specialized transducing phages (Chan \& Botstein, 1976). Since we have shown (Fig. 4) that the prophage attachment site is located in P22 EcoRI C, the insertion in P22 pro-3 must occur between EcoRI sites 3 and 4. From this information, the EcoRI cleavage map of P22 pro-3 DNA shown in Figure 8 was derived. If the pro-3

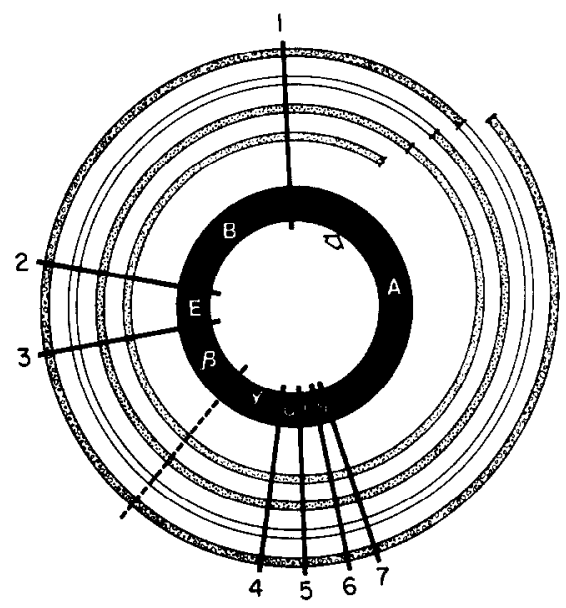

FIG. 8. Map of EcoRI cleavage sites and headful maturation cleavages in P22 pro-3 DNA. The circular EcoRI cleavage site map of P22 pro-3 DNA is diagrammed to scale. The P22 pro-3 genome is 103 to $104 \%$ of the size of P22 wild-type (Fig. 2). Symbols are as in Fig. 2. (-----) Designates the EcoRI cleavage site in the pro-3 insertion. The model for P22 DNA maturation described in Fig. 2 was used to predict the positions of molecular ends on the physical map. The average length of a headful, $103 \%$ of the P22 wild-type genome, was used to calculate the positions of DNA maturation cleavages shown. Since the genome of tho P22 pro-3 insertion mutant is about the same length or very slightly longer than the average length of a headful of DNA, all maturation cleavages occur near the pac site, and none of the mature linear chromosomes yield intact fragment A upon EcoRI cleavage.

insertion carries no EcoRI cleavage site, P22 EcoRI C will be replaced by a fragment equal to the molecular weight of P22 EcoRI C plus $3 \%$ of intact P22 DNA, or $5 \cdot 6 \times 10^{6}$. However, agarose gel electrophoresis of an EcoRI digest of P22 pro-3 DNA (Fig. $1(e)$ ) showed that no fragment $\mathrm{C}$ was present. Instead, a single new fragment $(\beta)$ of molecular weight $3.18 \times 10^{6}$ was seen. However, measurement of the amount of DNA in each band showed that the molar yield of band D is $155 \%$ compared to band $\mathbf{E}$ (Table 2(g)). Therefore, EcoRI cleavage at a site within the pro-3 insertion yields two new fragments, fragment $\beta$, and fragment $\gamma$ of molecular weight $2.65 \times 10^{6}$, which co-migrates with fragment $D$ during gel electrophoresis. The net size of the insertion calculated from the sum of the molecular weights of the two new fragments is $3.7 \%$ of the mature P22 chromosome, in good agreement with the value of $3 \%$ obtained from heteroduplex measurements by Chan \& Botstein (Chan, 1974; Chan $\&$ Botstein, 1976). The order of the fragments $\beta$ and $\gamma$ shown on the map in Figure 8 was obtained by comparing products of $H$ indIII and EcoRI digestion of P22 pro-3 
DNA with double digestion products of P22 wild-type DNA (R. J. Deans, unpublished experiments).

The packaging model applied to P22 pro-3 predicted a striking alteration in P22 $E c o$ RI cleavage products. The insertion results in a complete genome length nearly equal to the length of one headful. Therefore the ends of linear molecules encapsulated in sequential headfuls will all be close to the pac site at which encapsulation begins. The packaging model of Figure 2 is applied to P22 pro-3 in Figure 8. If packaging begins within EcoRI A at the site shown in the Figure, and one complete genome is about the same size or slightly larger than the average length of one headful, the ends of all the mature linears lie in EcoRI A near the pac site. The diagram predicts that no intact fragment $A$ will be found. The products of EcoRI cleavage of P22 pro-3 are shown in Figure 1(e). There is no intact fragment $A$ in the digest. This result shows conclusively that pac is located in A. Segments of fragment $A$ are found which have heterogeneous molecular weights between $9 \cdot 4 \times 10^{6}$ and $10 \cdot 0 \times 10^{6}$. This result positions pac within $4.5 \times 10^{3}$ bases of one end of EcoRI A. This result is in excellent agreement with the proposal that pac is $4.1 \times 10^{6}$ bases from $E c o$ RI site 1.

\section{(i) Physical locations of P22 genes}

The $E c o$ RI cleavage site maps of the deletion and insertion mutants used to analyze DNA packaging also allow some $\mathrm{P} 22$ genes to be positioned relative to P22 EcoRI cleavage sites. Chan \& Botstein prepared a physical map of a portion of the P22 genome near the prophage attachment site from genetic and heteroduplex analysis of Tc-10 and its deletion revertants (Chan, 1974; Chan \& Botstein, 1976). These studies precisely located the phage attachment site relative to the $t^{\mathrm{R}}$ insertion. This physical map is correlated with the EcoRI cleavage site maps of the insertion and deletion DNAs in Figure 4. We show that the right end of the bp5 deletion lies between P22 EcoRI sites 6 and 7. The size of the net deletion equals $16 \%$ the length of the wild-type P22 genome. Chan \& Botstein showed that a piece of the $t e t^{\mathrm{R}}$ insertion equal to $2 \%$ of P22 remains in bp5. This determination of the left-hand end of the deletion and the total size of the deletion places the end of the tet $^{\mathrm{R}}$ insertion with respect to $E c o$ RI cleavage site 3 as shown in Figure 4(a). The prophage attachment site is $2.5 \times 10^{3}$ bases from $t^{\mathrm{R}}$ (Chan, 1974), and lies between EcoRI sites 3 and 4 , at 0.4 on the physical gene map in the preceding paper (Jackson et al., 1978). int lies to the right of the attachment site, but under the bp5 and bpl deletions, so it is located to the right of $E c o$ RI site 3 and left of $E c o$ RI site 7 (Fig. 4(a)). We have not determined whether int is located on EcoRI fragments C, G or F. Gene erf is not deleted in bp5, so it is located to the right of EcoRI site 6 (Fig. 4(a)). erf must lie in either fragment $\mathbf{H}$ or $\mathbf{A}$.

\section{Discussion}

(a) Location of DNA packaging initiation site and direction of sequential encapsulations on the EcoRI cleavage site map of P22 DNA

The $E c o$ RI cleavage site map derived in this and the preceding paper (Jackson et al., 1978) is the first restriction endonuclease cleavage site map of a circularly permuted chromosome. Restriction enzyme cleavage of a random set of circularly permuted chromosomes should yield as visible bands on electrophoresis only the fragments generated by restriction endonuclease cleavages at both ends of the fragment. Many other fragments would result from one endonucleolytic cleavage 
near a molecular end, but if the ends were randomly distributed over the genome, these fragments would not form detectable bands. However, the P22 circular permutations are not random. The ends of the mature chromosomes fall over a limited portion of the physical map (Tye et al., 1974b). In this case, many linear molecules have approximately the same ends, and restriction enzyme cleavage generates enough fragments of similar size to form visible bands on agarose gel electrophoresis. These end fragments were used to map the location of molecular ends relative to the EcoRI site map, which in turn has been oriented relative to the genetic map (Jackson et al., 1978). Molecular ends fall at different positions in deletion or insertion mutant DNA, and end fragments from EcoRI digests of these DNAs allowed more maturation cleavage events to be mapped relative to EcoRI sites. From these physical locations for maturation cleavages and the known length of a headful, the position of the pac site and the direction of sequential packaging relative to the EcoRI cleavage site map could be deduced. P22 DNA maturation begins $4 \cdot 1 \times 10^{3}$ bases clockwise from $k c o R I$ site 1 and proceeds in the counterclockwise direction in Figure 2. Fragment D is produced by $E c o R I$ cleavage at site 1 near the end of a linear DNA molecule encapsulated starting at pac, or the first headful of DNA in a packaging sequence. One end of fragment $\mathrm{D}$ marks the location of pac within EcoRI fragment A. Ends of P22 wild-type linear chromosomes cleaved non-specifically during sequential packaging also fall in EcoRI fragment A, so that A is found in low yield, and slightly shorter segments of $A$ are found as the leading edge of band $A$ following gel electrophoresis. Since no short pieces of fragment A smaller than fragment $\mathrm{D}$ are found, although they should be produced from EcoRI cleavage of DNA packaged in the second and third headfuls, we suggest that the headful length varies slightly. The small variation in headful size is nevertheless a large proportion of the total size of these short fragments, leading to sufficient heterogenity in length that they are not observed as bands in gels (see Fig. 3). That the headful length should vary slightly is not surprising, and genetic experiments reported by Chan (1974) support this suggestion. Fragment D, however, is of invariant size, since it arises from two site-specific cleavages, one at pac, and one at EcoRI site 1. Since D is an end fragment and a segment of $E c o$ RI A, the other seven $E c o$ RI fragments ordered in the preceding paper define the positions of all EcoRI cleavage sites in P22 DNA. The sum of the molecular weights of these seven fragments $(A, B, C, E, F, G$ and $\mathrm{H}$ ) is $27.5 \times 10^{6}$, in excellent agreement with the value of $27.65 \times 10^{6}$ for the molecular weight of intact $\mathrm{P} 22$ less the $3 \%$ terminal redundancy (Rhoades et al., 1968; Tye et al., 1974; Jackson et al., 1978). This EcoRI cleavage site map is a circle, since P22 linear chromosomes are circularly permuted.

Tye et al. (1974b), following another experimental approach, first proposed that P22 DNA encapsulation begins at a unique genetic site and proceeds sequentially in one direction. Our results are additional evidence for this model of P22 DNA packaging. These experiments furthermore locate the specific site at which P22 DNA maturation begins, and the direction of sequential encapsulation relative to the EcoRI cleavage site map of P22 DNA.

\section{(b) EcoRI analysis of P22 DNA packaging}

Analysis of EcoRI cleavage products of P22 DNA provides a sensitive and simple means to study P22 headful packaging. Measurements of the relative yields of 
fragments derived from ends of linear molecules can be used to determine the proportion of linears packaged in first or subsequent headfuls. Since fragment $D$ comes only from chromosomes packaged at pac, the relative molar yield of $\mathrm{D}$ represents the fraction of linear chromosomes produced by the initial headful in a packaging sequence. Therefore, about one-third of the wild-type P22 linear chromosomes encapsulated are first headfuls (Table 2).

Electrophoresis of the P22 Tc-10 EcoRI digest yields bands uniquely characteristic of the first, second and third headfuls in a packaging sequence (Figs $1(d)$ and 7 ). P22 Tc-10 bands D and $\gamma$ are products of EcoRI cleavage of a first headful, band $\beta$ is produced only by cleavage of a second sequential headful, and band $\alpha$ comes only from cleavage of a linear packaged in a third sequential headful. The molar yield of each of bands $\gamma, \beta$ and $\alpha$ equals the proportion of linear chromosomes encapsulated in first, second or third headfuls. The molar yield data for band $\gamma$ in Table 2 show that about one-third of the linear chromosomes were packaged in initial headfuls. About one-quarter of the linears were packaged in a second headful (band $\beta$ ) or a third sequential headful (band $\alpha$ ). There is no band which uniquely distinguishes a fourth headful, but these results show that over $80 \%$ of the mature linear chromosomes were packaged in the first three sequential headfuls (Table 2). We expect that most packaging sequences do no extend beyond four headfuls. These results do not conflict with the data from which Tye et al. (1974b) concluded that the maximum number of headfuls in one sequence is ten. They showed that the ends of linear molecules are distributed over $20 \%$ of the physical map, and most ends fall within 10 to $15 \%$ of each other (Tye et al., 1974b). We have used the value of $103 \%$ for the length of one average headful, since calculations based on this figure give the best fit with the molecular weights of EcoRI fragments observed in P22 Tc-10 (Fig. 7). This value implies a terminal redundancy of $3 \%$, which falls within the range of lengths of terminal redundancies measured previously (Tye et al., 1974a). If the length of an average headful is $103 \%$ of one complete set of P22 genes, and if there are four headfuls in one sequence, the ends of linear molecules will fall over $12 \%$ of the physical map. Variability in headful size will cause the ends to be distributed over a slightly larger portion of the map, in good agreement with the previous data showing the distribution of molecular ends (Tye et al., 1974b).

The accompanying paper (Weaver \& Levine, 1978) further illustrates the utility of $E c o$ RI cleavage for study of P22 DNA packaging. They have analyzed EcoRI digests of the mixture of host and phage DNA obtained from defective particles produced following induction of a P22 prophage unable to excise from the host chromosome. The subset of P22 EcoRI fragments found indicates that the initiation site and direction of DNA packaging in this abnormal case is the same as in wild-type P22.

\section{(c) Genetic location of the packaging initiation site}

The physical map of $E c o$ RI cleavage sites in P22 DNA (Fig. 2) has been aligned with the P22 genetic map, and a number of P22 genes have been precisely located with respect to EcoRl cleavage sites (see Fig. 6 of Jackson et al., 1978). This physical gene map allows us to relate the physical map of packaging events (Fig. 2) to the genetic map. Packaging begins on the late gene side of gene 13, and moves in the counterclockwise direction with respect to the genetic map given in Figure 6 by Jackson et al. (1978), or away from the early gene region. Weaver \& Levine (1978) have also 
concluded that encapsulation of a P22 prophage unable to excise from the host chromosome is polarized in this same direction.

A fundamental question about the molecular basis of P22 DNA packaging concerns the nature of the interaction between $\mathrm{P} 22$ proheads and the packaging initiation site on the concatemeric DNA precursor (Tye et al., 1974b; Tye, 1976). The nucleotide sequence corresponding to this site occurs in each monomeric repeating unit of the concatemer. Yet a packaging sequence begins only once per three or four genome repeats. Tye et al. (1974b) suggested that the unique site at which encapsulation begins is a free end of the concatemeric DNA at the tail of a rolling circle. Thus the unique genetic site for phage DNA encapsulation would be located at the site of origin of P22 DNA synthesis. Our data now exclude this interpretation. The only known site for initiation of P22 DNA replication lies in the vicinity of DNA synthesis genes 12 and 18 (Hilliker \& Botstein, 1976). Genes 12 and 18 can be placed in frag. ment $A$ at a maximum distance of $11 \times 10^{3}$ bases from P22 EcoRI cleavage site 7 from consideration of $\lambda$ immP22hy37 (Jackson et al., 1978). The site of packaging initiation is $15.9 \times 10^{3}$ bases from site 7 (Fig. 2). The physical map shows unequivocally that the packaging initiation site is not located at genes 12 and 18 , and therefore is unlikely to be a free end produced by DNA replication. Weaver \& Levine (1978) concluded that during induction of a P22 int- lysogen, all regions of the P22 genome are replicated, although only part of the prophage sequences are encapsulated. This result is additional evidence that DNA replication is not the sole determinant of encapsulation specificity.

All available data suggest that the pac site is near gene 3. Since $\lambda$ immP22hy38 includes P22 gene 13 within less than $15 \times 10^{3}$ bases of DNA from site 7 (in counterclockwise direction in Fig. 2) (Jackson et al., 1978), and the packaging origin is $15.9 \times 10^{3}$ bases counterclockwise from site 7 , the site at which headful packaging begins lies beyond gene 13 . These results are in agreement with approximate locations for the packaging initiation site obtained by genetic methods which place the site within the following genetic region: genes 1812131932 . Analysis of the plating efficiency of P22 pro-3 on various P22 deletion lysogens led Chan to suggest that the packaging origin lies at one or the other end of the region encompassing genes 12 through 3 (Chan, 1974). From study of excision-defective P22 lysogens, Weaver \& Levine (1978) conclude that this site is to the left of gene 2 in the gene order given above, and they suggest that the site may be in or near gene 3 . We have shown that it is to the right of gene 13 . These various lines of evidence taken together indicate that the packaging initiation site lies in the vicinity of genes 19 and 3 .

\section{(d) P22 DNA encapsulation and maturation may resemble the $\lambda$ mechanisms}

Although the organization of genes in the early region of the $\lambda$ and P22 genetic maps are similar, the mature form of the chromosomes of the two viruses are quite different. P22 linear DNA molecules have circularly permuted ends, while $\lambda$ chromosomes have unique ends. Since the final form of a mature phage chromosome is a consequence of the mechanism by which DNA is cut from the concatemer, the mechanisms by which P22 and $\lambda$ process DNA during encapsulation were thought to be fundamentally different (Tye, 1976; Botstein et al., 1972; Feiss \& Bublitz, 1975). However, our results, when considered together with recent work on $\lambda$ DNA maturation, show that P22 and $\lambda$ DNA maturation mechanisms have many common properties. 
The product of P22 gene 3 may be directly involved in cutting the concatemer at the packaging initiation site (Botstein et al., 1973; 'Tye, 1976; Raj et al., 1974). The position of gene 3 on the P22 genetic map is analogous to the genetic location of $\lambda$ gene $A$, which is thought to specify the nuclease which cleaves $\lambda$ concatemers during $\lambda$ maturation (Botstein et al., 1972; Wang \& Kaiser, 1973). Both P22 gene 3 and $\lambda$ gene $A$ map adjacent to lysis genes at one end of the clustered head genes. We favor the proposal that interaction of the product of gene 3 at pac is required to begin a sequence of headfuls at the packaging initiation site. Gene 3 product may have endonucleolytic activity, or may control the activity of another nuclease (Tye, 1976; Botstein et al., 1973; Raj et al., 1974).

The P22 packaging initation site has been located in a region on the P22 chromosome including genes 19 and 3 (see above; Chan, 1974; Weaver \& Levine, 1978). The $\lambda \cos$ site, at which the $\lambda$ site-specific nuclease acts to cut the concatemeric DNA precursor, lies between lysis genes and head genes adjacent to gene $A$, a region of the $\lambda$ map analogous to the region between P22 genes 19 and 3 . The physical location of the P22 packaging initiation site corresponds to $\lambda \cos$ as well. When the physicalgenetic map of a P22 chromosome which was encapsulated at the packaging initiation site is aligned at the prophage attachment site with the physical gene map of $\lambda$, the ends of the right arms which mark the physical locations of pac and cos are closely aligned (sce Fig. 7 of the preceding paper, Jackson et al., 1978). Thus the physical and genetic map locations of the genes which specify or control a DNA maturation nuclease and the specific site of action of the nuclease are similar in P22 and $\lambda$.

Headful packaging of sequential headfuls of P22 DNA proceeds in one direction along a concatemer (Tye et al., 1974b). The direction of packaging is away from early genes and lysis genes, or counterclockwise (Fig. 2). $\lambda$ chromosomes also are packaged and cut from a concatemer sequentially, with the last eut made in packaging one chromosome serving as the first cut in maturation of the next (Emmons, 1974; Feiss \& Bublitz, 1975). The processive packaging and cutting of $\lambda$ DNA occurs in only one direction along the concatemer. $\lambda$ processive packaging is polarized in the same direction relative to the genetic map as P22 sequential packaging (Feiss \& Bublitz, 1975; Sternberg \& Weisberg, 1975). The number of $\lambda$ chromosomes packaged in a sequence is two to three (Emmons, 1974; Feiss \& Bublitz, 1975), while three to four P22 headfuls are encapsulated sequentially (Table 2).

\section{(e) Initiation of a packaging sequence}

What limits the length of a packaging sequence? $\lambda$ DNA concatemers ten times the length of mature $\lambda$ DNA have been reported (Skalka, 1971). Emmons (1974) proposed that a $\lambda$ packaging sequence can initiate at any cos site on a concatemer. Feiss \& Bublitz (1975) suggest that several packaging sequences are initiated at random on one concatemer. P22 DNA concatemers ten genomes long have been reported in the abscnce of head assembly and DNA processing (Botstein, 1968; Botstein \& Levine, 1968; Botstein et al., 1973). We show here that most $\mathrm{P} 22$ packaging sequences comprise three to four headfuls. These data suggest that $\mathrm{P} 22$ can initiate several packaging sequences on one concatemer, and the length of a packaging sequence reflects the probability that gene 3 product will interact with a pac site. We offer two suggestions to explain why only one in every three pac sites on a concatemer is cleaved. Perhaps gene 3 product competes with encapsidation for free pac sites. Alternatively, gene 3 product might be made in low amounts and would act non- 
catalytically. In this case, pac sites would be in excess over specific nucleolytic activity, and only one in three sites could be cleaved. Previous workers suggested that P22 initiates a headful packaging sequence once per concatemer at a free end of DNA which might be the tail of a rolling circle DNA replication intermediate (Tye et $a l ., 1974 b$; Tye, 1976). Our data indicate that this is not the case. We propose instead that a packaging sequence begins when the product of gene 3 interacts with a packaging initiation site, with the result that the concatemer is cleaved at pac. Such initiation events would occur randomly along the concatemer with a probability of about one-third for each pac site. Several headful sequences could initiate on a single concatemer.

$\lambda$ and P22 DNA packaging begin in the same genetic region and depend on the acitivity of genes of equivalent map location. Both phages package DNA in short sequences of headfuls, with sequential headfuls forming along the concatemer in the same genetic direction. The two DNA packaging mechanisms differ principally in the requirements for the second cleavage that completes maturation of a linear DNA molecule. $\lambda$ requires a specific nucleotide sequence to make this cut; P22 does not. The similarity of $\lambda$ and P22 DNA packaging is further illustrated by the fact that encapsulation of excision-defective prophage DNA is identical for P22 and $\lambda$, except that $\lambda$ cannot cleave bacterial DNA after packaging it into the phage head and P22 can (Sternberg \& Weisberg, 1975; Weaver \& Levine, 1978).

Interesting aspects of the P22 DNA maturation process remain obscure. What events initiate a packaging sequence? Why do packaging sequences begin at only one-third of the pac sites? How does encapsulation of DNA at the packaging initiation site differ from encapsulation of the second headful in the sequence? How do nonspecific DNA cleavages occur? Does the same nuclease perform both nucleotide sequence-specific and non-specific DNA cleavages? EcoRI cleavage of P22 DNA provides a simple and sensitive experimental tool to study P22 DNA packaging. We are currently utilizing these methods to study mutants of P22 defective in packaging to learn more about the mechanism of P22 DNA maturation.

David Botstein and collaborators generously provided the insertion and deletion derivatives of P22 on which this work depends. We thank Tony Weighous for outstanding technical assistance, and Robert J. DeLeys for help with densitometric analysis. We also thank Steven Weaver and Myron Levine for access to unpublished data, and William Folk, David Friedman and Myron Levine for criticism of the manuseript. This work was supported by a grant from the National Institutes of Health (grant no. AI-12369).

\section{REFERENCES}

Botstein, D. (1968). .J. Mol. Biol. 34, 621-641.

Botstein, D. \& Levine, M. (1968). J. Mol. Biol. 34, 643-654.

Botstein, D., Chan, R. K. \& Waddell, C. H. (1972). Virology, 49, 268-282.

Botstein, D., Waddell, C. \& King, J. (1973). J. Mol. Biol. 80, 669-695.

Chan, R. K. (1974). Ph.D. thesis, Massachusetts Institute of Technology.

Chan, R. K. \& Botstein, D. (1976). Genetics, 83, 433-458.

Chan, R. K., Botstein, D., Watanabe, T. \& Ogata, Y. (1972). Virology, 50, 883-898.

DeLeys, R. J. \& Jackson, D. A. (1976). Nucl. Acids Res. 3, 641-652.

Denhardt, D. T. (1966). Biochem. Biophys. Res. Commun. 23, 641-646.

DeVries, F. A. J., Collins, C. J. \& Jackson, D. A. (1976). Biochim. Biophys. Acta, 435, $213-227$.

Emmons, S. W. (1974). J. Mol. Biol. 83, 511-525.

Feiss, M. \& Bublitz, A. (1975). J. Mol. Biol. 94, 583-594. 
Helling, R. B., Goodman, H. M. \& Boyer, H. W. (1974). J. Virol. 14, 1235-1244.

Hilliker, S. \& Bolstein, D. (1976). J. Mol. Bivl. 106, 537-566.

Jackson, E. N., Miller, H. I. \& Adams, J. L. (1978). J. Mol. Biol. 118, 347-363.

Jessop, A. P. (1976). Genetics, 83, 459-475.

Raj, A. S., Raj, A. Y. \& Schmieger, H. (1974). Mol. Gen. Genet. 135, 175184.

Rhoades, M., MacHattie, L. A. \& Thomas, C. A. Jr (1968). J. Mol. Biol. 37, 21-40.

Skalka, A. (1971). In The Bacteriophage Lambda (Hershey, A. D., ed.), pp. 535-547, Cold Spring Harbor Press, New York.

Smith, H. O. \& Levine, M. L. (1964). Proc. Nat. Acad. Sci., U.S.A. 52, 356-363.

Sternberg, N. \& Weisberg, R. (1975). Nature (London), 256, 97-103.

Streisinger, G., Emrich, J. \& Stahl, M. M. (1967). Proc. Nat. Acad. Sci., U.S.A. 57, 292-295.

Thomas, M. \& Davis, R. W. (1975). J. Mol. Biol. 91, 315-328.

Tye, B. K. (1976). J. Mol. Biol. 100, 421-426.

Tye, B. K., Chan, R. K. \& Botstein, D. (1974a). J. Mol. Biol. 85, 485-500.

Tye, B. K., Huberman, J. A. \& Botstein, D. (1974b). J. Mol. Biol. 85, 501-532.

Wang, J. C. \& Kaiser, A. D. (1973). Nature New Biol. 241, 16-17.

Watanabe, T., Ogata, Y., Chan, R. K. \& Botstein, D. (1972). Virology, 50, 874-882.

Weaver, S. \& Levine, M. (1978). J. Mol. Biol. 118, 389-411. 